\title{
ERRATUM
}

M. Schieppati $\cdot$ A. Nardone $\cdot$ R. Siliotto $\cdot$ M. Grasso

\section{Early and late stretch responses of human foot muscles induced by perturbation of stance}

Exp Brain Res (1995) 105:411-422

Table 4, p. 416, must be replaced with the following:

Table 4 Mean latencies ( \pm SD) of the SLR and MLR of Sol and FDB used in four subjects to calculate the interval $(b-a)$. The means and SDs appearing in the column Extra delay are obtained by averaging, trial by trial, the $n$ values of the differences (MLR FDB-MLR Sol)-(SLR FDB--SLR Sol) ( $n$ number of trials in which both SLR and MLR occurred concurrently in both muscles). $P$ is obtained by applying Student's $t$-test for paired data to the above differences. The conduction time for the group Ia fibres was calculated on the basis of the mean conduction velocity of these fibres (54.7 ms/s) (Macefield et al. 1989). The conduction velocity of the group II fibres was then obtained by dividing the distance between the muscles by the total conduction time for group II fibres. This was the sum of the conduction time for Ia plus the extra delay $(b-a)$

\begin{tabular}{|c|c|c|c|c|c|c|c|c|c|c|}
\hline \multirow[t]{2}{*}{ Subject } & \multicolumn{2}{|l|}{ Sol } & \multicolumn{2}{|l|}{ FDB } & \multirow{2}{*}{$\begin{array}{l}\text { Conduction } \\
\text { time for Ia } \\
\text { fibres (ms) }\end{array}$} & \multirow{2}{*}{$\begin{array}{l}\text { Extra } \\
\text { delay } \\
(\mathrm{b}-\mathrm{a}) \\
(\mathrm{ms})\end{array}$} & \multirow[t]{2}{*}{$n$} & \multirow{2}{*}{$\begin{array}{l}\text { Conduction } \\
\text { time for } \\
\text { II fibres } \\
\text { (ms) }\end{array}$} & \multirow{2}{*}{$\begin{array}{l}\text { Distance } \\
(\mathrm{cm})\end{array}$} & \multirow{2}{*}{$\begin{array}{l}\text { Conduction } \\
\text { velocity of } \\
\text { II fibres } \\
(\mathrm{m} / \mathrm{s})\end{array}$} \\
\hline & SLR (ms) & MLR (ms) & SLR (ms) & $\operatorname{MLR}(\mathrm{ms})$ & & & & & & \\
\hline C.U. & $40.0 \pm 1.9$ & $67.3 \pm 2.6$ & $55.6 \pm 3.3$ & $89.6 \pm 4.7$ & 3.8 & $\begin{array}{l}6.7 \pm 7.4 \\
(P<0.02)\end{array}$ & 12 & 10.5 & 21.0 & 20.0 \\
\hline M.S. & $44.2 \pm 2.3$ & $72.4 \pm 5.4$ & $64.2 \pm 3.1$ & $101.8 \pm 3.2$ & 4.9 & $\begin{array}{l}9.3 \pm 9.2 \\
(P<0.001)\end{array}$ & 31 & 14.2 & 27.0 & 19.0 \\
\hline A.N. & $45.8 \pm 1.9$ & $74.0 \pm 3.5$ & $62.5 \pm 1.7$ & $98.0 \pm 5.5$ & 3.7 & $\begin{array}{l}7.4 \pm 6.7 \\
(P<0.001)\end{array}$ & 41 & 11.1 & 20.4 & 18.4 \\
\hline S.A. & $42.9 \pm 1.3$ & $68.0 \pm 3.7$ & $62.7 \pm 1.6$ & $96.9 \pm 4.1$ & 4.7 & $\begin{array}{l}9.1 \pm 5.1 \\
(P<0.001)\end{array}$ & 11 & 13.8 & 26.0 & 18.8 \\
\hline
\end{tabular}

The estimated mean conduction velocity of the fibres responsible for the FDB MLR thus becomes $19.1 \pm 0.7 \mathrm{~m} / \mathrm{s}$. Therefore,"about $29 \mathrm{~m} / \mathrm{s}$ " must be corrected to "about $19 \mathrm{~m} / \mathrm{s}$ " in the text (Abstract,

p. 411, line 29; Discussion, p. 419, right column, line 17). This modification does not change the conclusions of the paper 